\title{
Effects of ageing on pro-arrhythmic ventricular phenotypes in incrementally paced murine $\mathrm{Pgc}-1 \beta^{-/-}$hearts
}

\author{
Shiraz Ahmad ${ }^{1}$ - Haseeb Valli ${ }^{1}$. Charlotte E. Edling ${ }^{2}$ Andrew A. Grace ${ }^{3}$. \\ Kamalan Jeevaratnam ${ }^{1,2,4}$ • Christopher L-H Huang ${ }^{1,3}$
}

Received: 14 July 2017 /Revised: 2 August 2017 / Accepted: 3 August 2017 /Published online: 18 August 2017

(C) The Author(s) 2017. This article is an open access publication

\begin{abstract}
A range of chronic clinical conditions accompany cardiomyocyte energetic dysfunction and constitute independent risk factors for cardiac arrhythmia. We investigated proarrhythmic and arrhythmic phenotypes in energetically deficient C57BL mice with genetic ablation of the mitochondrial promoter peroxisome proliferator-activated receptor- $\gamma$ coactivator- $1 \beta$ (Pgc-1 $\beta)$, a known model of ventricular arrhythmia. Proarrhythmic and cellular action potential (AP) characteristics were compared in intact Langendorff-perfused hearts from young (1216 week) and aged (> 52 week), wild-type (WT) and $P g c-1 \beta^{-/}$ mice. Simultaneous electrocardiographic and intracellular microelectrode recordings were made through successive trains of 100 regular stimuli at progressively incremented heart rates. Aged $P g c-1 \beta^{-1}$ hearts displayed an increased incidence of arrhythmia compared to other groups. Young and aged $\mathrm{Pgc}-1 \beta^{-/}$hearts showed higher incidences of alternans in both AP activation (maximum AP upshoot velocity $(\mathrm{d} V / \mathrm{d} t)_{\max }$ and latency), recovery (action potential duration $\left(\mathrm{APD}_{90}\right)$ and resting membrane potential (RMP) characteristics compared to WT hearts. This was particularly apparent at lower pacing frequencies. These findings
\end{abstract}

Shiraz Ahmad

sa416@cam.ac.uk

Christopher L-H Huang

clh11@cam.ac.uk

1 Physiological Laboratory, University of Cambridge, Downing Street, Cambridge CB2 3EG, UK

2 Faculty of Health and Medical Sciences, University of Surrey, Guildford, Surrey GU2 7AL, UK

3 Department of Biochemistry, University of Cambridge, Tennis Court Road, Cambridge CB2 1QW, UK

4 PU-RCSI School of Medicine, Perdana University, 43400 Serdang, Selangor Darul Ehsan, Malaysia accompanied reduced $(\mathrm{d} V / \mathrm{d} t)_{\max }$ and increased AP latency values in the $P g c-1 \beta^{-/}$hearts. APs observed prior to termination of the protocol showed lower $(\mathrm{d} V / \mathrm{d} t)_{\max }$ and longer AP latencies, but indistinguishable $\mathrm{APD}_{90}$ and RMPs in arrhythmic compared to those in non-arrhythmic hearts. APD restitution analysis showed that $P g c-1 \beta^{-/}$and WT hearts showed similar limiting gradients. However, $P g c-1 \beta^{-1}$ hearts had shortened plateau AP wavelengths, particularly in aged $P g c-1 \beta^{-/}$hearts. $P g c-1 \beta^{-/}$hearts therefore show pro-arrhythmic instabilities attributable to altered AP conduction and activation rather than recovery characteristics.

Keywords Peroxisome proliferator-activated receptor- $\gamma$ coactivator-1 (PGC-1) · Ventricles · Action potential · Wavelength $\cdot$ Cardiac conduction $\cdot$ Cardiac arrhythmias

\section{Introduction}

Following the successful mechanistic and mathematical description of the cardiac action potential and its propagation, cardiac electrophysiology has increasingly focused upon the physiological mechanisms underlying arrhythmia [19]. The risk of cardiac rhythm abnormalities accumulates with age. The prevalence of atrial fibrillation rises from $\sim 4 \%$ of individuals aged $60-70$ to $\sim 20 \%$ at $>80$ years [54], while the incidence of sudden cardiac death attributable to ventricular arrhythmias is eight times higher in 75- than 50-year-old individuals [8]. Metabolic abnormalities associated with chronic, age-dependent, conditions including obesity, insulin resistance, diabetes mellitus and heart failure also accentuate arrhythmic risk, independently of any ischaemic changes arising from associated coronary vascular effects $[1,28,51]$. These situations are accompanied by cardiomyocyte energetic and therefore, mitochondrial dysfunction, itself an independent arrhythmic risk factor [2]. Thus, inherited mitochondrial 
disorders such as Kearns-Sayre syndrome predispose to fatal ventricular arrhythmias [24]. Fibrotic defects of the cardiac conduction system leading to heart block are similarly agerelated and contribute to age-dependent onsets of inherited arrhythmic conditions including the Brugada syndrome [22].

The peroxisome proliferator-activated receptor- $\gamma$ coactivator-1 (PGC-1) family of transcriptional coactivators offers a strategic target for studying the electrophysiological consequences of energetic deficiency. PGC-1 regulates mitochondrial mass, function and cellular metabolism [13], upregulating nuclear and mitochondrial gene expression involved in fatty acid $\beta$-oxidation, the tricarboxylic acid cycle and the electron transport chain [3]. PGC-1 protein expression and, correspondingly, mitochondrial activity vary with upstream cellular energy demand [44]. Metabolic conditions such as obesity, insulin resistance and type II diabetes as well as advanced age are associated with reduced PGC-1 protein expression and mitochondrial dysfunction $[9,30,36]$.

Much of the biochemical insight into the consequences of cardiac energetic deficiency $[21,38]$ derives from studies in hearts with dysfunctional PGC-1 networks [4, 20]. Pgc-1 $\alpha^{-/}$ murine hearts show normal baseline contractility, developing heart failure only with increased afterload [3]. Pgc-1 $\beta^{-1}$ hearts similarly show normal baseline cardiac function, but display compromised heart rate responses with adrenergic stimulation [29]. Langendorff-perfused $\mathrm{Pgc}-1 \beta^{-/}$hearts demonstrated preliminary evidence for increased arrhythmogenicity. Their isolated cardiomyocytes showed diastolic $\mathrm{Ca}^{2+}$ transients, afterdepolarisation events and altered ion channel expression patterns [17], abnormalities also known to occur with ageing [18].

The combination of normal contractile function with proarrhythmic electrophysiological changes suggests that $\mathrm{Pgc}$ $1 \beta^{-/-}$hearts are suitable models to explore the proarrhythmic effects of mitochondrial impairment. Isolated, perfused, murine hearts have proved to be useful in the study of arrhythmic phenotypes and their underlying mechanisms. They have been particularly important in studies of specific genetic modifications directed at well-defined, inherited, monogenic ion channelopathies $[19,22,25]$. The present study extends these analyses to $P g c-1 \beta^{-/}$hearts through the analysis of the electrophysiological consequences of energetic dysfunction. Chronic mitochondrial lesions likely exert cumulative and time-varying phenotypic effects with advancing age, and so the experiments studied both young and aged, wild-type (WT) and genetically modified animals.

\section{Methods}

\section{Animals}

This research has been regulated under the Animals (Scientific Procedures) Act 1986 Amendment Regulations 2012 following ethical review by the University of Cambridge Animal Welfare and Ethical Review Body (AWERB). The experiments also conformed to the Guide for the Care and Use of Laboratory Animals, U.S. National Institutes of Health (NIH Publication No. 85-23, revised 1996). Mice were housed in an animal facility at $21{ }^{\circ} \mathrm{C}$ with 12 -h light/dark cycles. Animals were fed sterile chow (RM3 Maintenance Diet; SDS, Witham, Essex, UK) and had free access to water, bedding and environmental stimuli. Mice were sacrificed by cervical dislocation. No recovery, anaesthetic or surgical procedures were required. Wild-type (WT) C57/B6 and $P g c-1 \beta^{-/}$adult mice were bred for the experimental protocols. $P g c-1 \beta^{-/}$mice were generated as described previously $[17,29]$. Briefly, a triple LoxP targeting vector was used, containing a floxed neomycin phosphotransferase selectable marker cassette inserted into intron 3 and a single LoxP site inserted into intron 5. This resulted in the deletion of exons 4 and 5. The presence of LoxP sites was confirmed in embryonic stem cells using southern blot analysis. Heterozygous triple LoxP mice crossed with ROSA26-Cre mice generated heterozygous $P g c-1 \beta^{-1}$ mice, which were further bred to generate homozygous $P g c-1 \beta^{-/}$mice. Mice were bred on a C57/B6 background to avoid possible strain-related confounds. Experiments were performed in four experimental groups: young WT $(n=23)$, young $P g c-1 \beta^{-/}(n=21)$, aged WT $(n=19)$ and aged Pgc$1 \beta^{-/}(n=25)$. All young mice were aged between 12 and 16 weeks and aged mice greater than 52 weeks.

\section{Buffering media}

All solutions used were based on Krebs-Henseleit (KH) solution (mM: NaCl, $119 ; \mathrm{NaHCO}_{3}, 25 ; \mathrm{KCl}, 4.0 ; \mathrm{KH}_{2} \mathrm{PO}_{4}, 1.2$; $\mathrm{MgCl}_{2}, 1.0 ; \mathrm{CaCl}_{2}, 1.8$; glucose, 10 ; and Na-pyruvate, $2.0 ; \mathrm{pH}$ adjusted to 7.4 and bubbled with $95 \% \mathrm{O}_{2} / 5 \% \mathrm{CO}_{2}$ (British Oxygen Company, Manchester, UK). Chemical agents were purchased from Sigma-Aldrich (Poole, UK). A modified KH solution containing $\mathrm{KH}$ mixed with $20 \mu \mathrm{M}$ blebbistatin (Selleckhem, Suffolk, UK) [10-12, 23] was used for perfusion to immobilise hearts prior to plain Krebs-Henseleit perfusion.

\section{Whole-heart intracellular microelectrode recordings}

Prior to sacrifice, 200 IU of unfractionated heparin (SigmaAldrich, Poole, UK) was administered intraperitoneally. Animals were then sacrificed and rapid sternectomy and cardiectomy were performed. All hearts were macroscopically unremarkable with no obvious abnormalities. Hearts were rapidly cannulated and secured as previously described [33, 39, 52] before being mounted on a horizontal Langendorff apparatus that was electrically insulated and incorporated into an intracellular rig within a Faraday cage, incorporating a light microscope (objective $\times 5$, eyepiece $\times 5$; W. Watson and Sons Limited, London, UK), organ bath and custom-built microelectrode amplifier and head stage. 
Hearts were mounted in a standard anatomical position to allow impalement of the left ventricular mass and pacing from the right ventricle simultaneously. The positioning of the recording and stimulating electrodes was controlled by two precision micromanipulators (Prior Scientific Instruments, Cambs., UK), calibrated to permit impalements over the same region of the myocardium. Stimulating and recording electrodes were positioned at consistent sites against the lateral surface of the right ventricle and the proximal left ventricle respectively to avoid confounds of regional differences in action potential (AP) characteristics. Accordingly, in any given experiment, alterations in AP latencies, measured as the time elapsed between the pacing stimulus and peak of the AP, reflected alterations in AP conduction velocities. Hearts were perfused with KH solution (at a constant flow rate of $2.1 \mathrm{ml} \mathrm{min}^{-1}$ ) for at least $5 \mathrm{~min}$ to reach steady state, before being perfused with $\mathrm{KH}$ solution and $20 \mu \mathrm{M}$ blebbistatin to minimise motion, before resumption of perfusion with plain $\mathrm{KH}$ solution. Preparations which did not show a regular intrinsic rhythm with a basic cycle length (BCL) of $<200 \mathrm{~ms}$ and 1:1 atrioventricular (AV) conduction for $>10$-min post-cannulation were not studied further. A conventional sharp 3-M $\mathrm{KCl}$-filled microelectrode (tip resistance 15-25 $\mathrm{M} \Omega$, filled with $3 \mathrm{M} \mathrm{KCL}$ ) was pulled by a custom-built microelectrode puller from a glass pipette $(1.2 \mathrm{~mm}$ OD, $0.69 \mathrm{~mm}$ ID; Harvard Apparatus) and then inserted into a right-angled microelectrode holder (Harvard Apparatus, Kent, UK). This was connected to the headstage of a high-input impedance directcurrent microelectrode amplifier system (University of Cambridge, Cambridge, UK). Following band-pass filtering between 0 and $2 \mathrm{kHz}$ and amplification, the signal was passed through an analogue to digital converter at a sampling frequency of $10 \mathrm{kHz}$ (1401; Cambridge Electronic Design, Cambs., UK). Successful impalement was indicated by the abrupt appearance of a resting membrane potential lower than $-70 \mathrm{mV}$ and regular action potentials of stable waveform. All measurements of intracellular voltage were made relative to the bath solution via a reference $\mathrm{Ag} / \mathrm{AgCl}$ electrode.

\section{Whole-heart electrocardiographic recordings}

Electrocardiographic (ECG) recordings of isolated Langendorff-perfused hearts were obtained simultaneously with intracellular microelectrode measurements to enable correlations between whole-organ rhythms and intracellular voltage changes. Recordings were made using two unipolar ECG electrodes placed at fixed positions around the heart in the organ bath, corresponding to the standard three-lead ECG coordinates. The recorded signals were passed through headstages for pre-amplification, prior to amplification (Neurolog NL104 amplifier) and band-pass filtering (between 5 and $500 \mathrm{~Hz}$; NL 125/6 filter; Digitimer, Herts, UK) before being digitized at a sampling frequency of $10 \mathrm{kHz}(1401$; Cambridge Electronic Design).

\section{Pacing protocols}

Hearts were stimulated at two times the threshold voltage plus $0.5 \mathrm{mV}$. Hearts underwent two pacing protocols. A standardised S1S2 protocol consisted of trains of eight stimuli delivered $125 \mathrm{~ms}$ apart (S1 stimuli) followed by an extrasystolic (S2) stimulus delivered initially at $90 \mathrm{~ms}$ after the previous $\mathrm{S} 1$ stimulus. This pattern of stimulation was repeated with the S2-S1 interval decremented by $1 \mathrm{~ms}$ for each successive cycle until failure of capture. Incremental pacing protocols began at a $130 \mathrm{~ms}$ basic cycle length (BCL) before being decremented by $5 \mathrm{~ms}$ for each subsequent cycle of 100 stimulations. This cycle was repeated until the heart showed entry into 2:1 block or arrhythmia.

\section{Data and statistical analysis}

Data was captured with Spike2 software (Cambridge Electronic Design) and then analysed using a custom-written program using the python programming language. Alternans was defined as beat to beat changes in the value of a parameter such that the direction of the change oscillates for at least ten successive action potentials. All statistical analysis was carried out using the R programming language [40] and plots with the grammar of graphics package [49]. All data is expressed as mean \pm standard error of mean (SEM) and a $p$ value of less than 0.05 taken to be significant. The different experimental groups were compared with a two-factor analysis of variance (ANOVA). $F$ values that were significant for interactive effects prompted post hoc testing with Tukey honestly significant difference testing. If single comparisons were made, a two-tailed Student's $t$ test was used to compare significance. Categorical variables were compared using Fisher's exact test. Kaplan-Meier estimates were compared with the log-rank test.

\section{Results}

We performed simultaneous electrocardiographic (ECG) wholeheart recordings and action potential (AP) measurements from single cardiomyocytes in intact ex vivo Langendorff-perfused hearts. Each procedure began with a programmed electrical stimulation protocol interposing extrasystolic (S2) stimuli at successively decremented intervals following trains of eight regular (S1) stimuli applied at a $125 \mathrm{~ms}$ basic cycle length (BCL). Overall ventricular electrical activity through the S1S2 protocol was monitored by the ECG recordings. Analysis of these initial recordings yielded ventricular effective refractory periods (VERPs) that indicated the extent to which BCLs could be decreased in the succeeding experiments. A comparison of VERPs 
in young and aged, WT $(57.36 \pm 2.06$ and $56.3 \pm 1.96 \mathrm{~ms}$, respectively) and $P g c-1 \beta^{-/}$(53.99 \pm 2.2 and $47.64 \pm 1.84 \mathrm{~ms}$, respectively) hearts demonstrated that $P g c-1 \beta^{-1-}$ hearts showed shorter VERPs than WT hearts $(56.88 \pm 1.42$ vs $50.54 \pm 1.48 \mathrm{~ms}$; $n=42$ vs $46 ; p<0.01$ ), without effects of either age or interactions between age and genotype.

Intracellular microelectrode recordings of cardiomyocyte APs within left ventricular epicardia were then obtained in parallel with ECG recordings of isolated Langendorff hearts during an incremental pacing protocol. Trains of 100 regular stimuli were imposed at BCLs progressively shortened by $5 \mathrm{~ms}$ with each successive stimulus train. These examined for the presence of arrhythmic activity and alternans in AP parameters related to their activation or recovery. Figure 1 tracks the progress of the experiments through the incremental pacing protocol in all the four groups, using Kaplan-Meier plots of the probability of hearts showing regular 1:1 evoked activity with decreasing BCL. Quantitative analysis was performed for BCLs up to $55 \mathrm{~ms}$, after which insufficient hearts showed regular 1:1 capture for analysis. The BCLs at which hearts failed to follow the repetitive pacing and entered 2:1 block reflect their VERP at that particular pacing rate. A log-rank test demonstrated that the Kaplan-Meier curves from the different experimental groups (Fig. 1) showed significant differences from each other $(p<0.01)$. VERPs at the termination of the protocol (young WT, $64.35 \pm 2.16 \mathrm{~ms}$; aged WT, $61.84 \pm 2.33 \mathrm{~ms}$; young $P g c$ $1 \beta^{-/}, 68.33 \pm 1.26 \mathrm{~ms}$; aged $P g c-1 \beta^{-/}$hearts, $61.0 \pm 1.83 \mathrm{~ms}$ ) were obtained from the BCLs achieved just prior to the onset of 2:1 atrioventricular conduction block.

\section{Age-dependent arrhythmic phenotypes in $\mathrm{Pgc}-1 \boldsymbol{\beta}^{-/-}$ hearts}

Figure 2 exemplifies intracellular electrophysiological traces of normal, arrhythmic and pro-arrhythmic activities from all

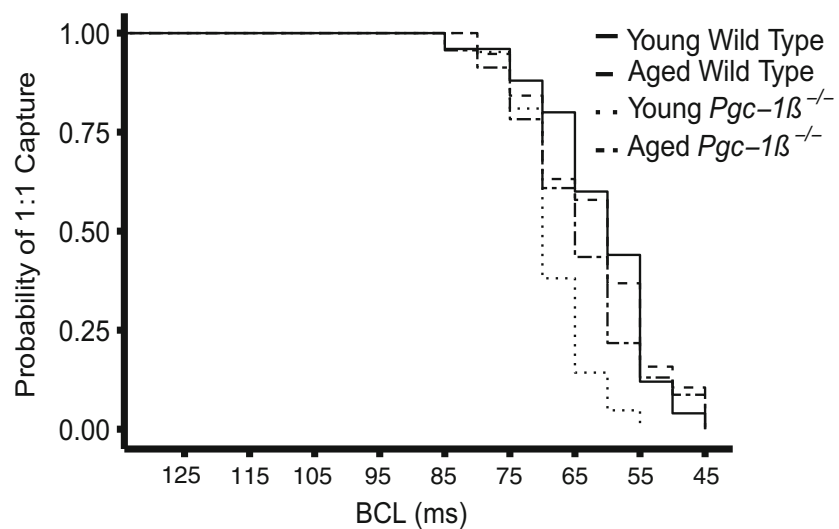

Fig. 1 Kaplan-Meier plot of the proportion of young and aged WT and $P g c-1 \beta^{-/}$hearts showing regular activity with increasing pacing frequency with the progressive fall off at higher pacing frequencies resulting in hearts losing capture and entering either 2:1 conduction block or arrhythmia the four experimental groups obtained in the course of the incremental pacing protocol. Figure 2 compares parallel ECG (i) and intracellular AP recordings (ii) of regular ventricular activity at a BCL of $130 \mathrm{~ms}$ from a young WT mouse (a). Similar simultaneous ECG (i) and intracellular AP recordings (ii) recordings made it possible to detect ectopic beats (b), monomorphic ventricular tachycardia (VT) (c) and torsades de pointes (TdP) (d) in aged $P g c-1 \beta^{-/}$hearts. Under these experimental conditions, there were no observations of spontaneous early or delayed afterdepolarisations. The latter have been reported in other pro-arrhythmic murine systems where they have been implicated in arrhythmic triggering [5, 6, 14].

Table 1 quantifies the occurrence of arrhythmic phenomena in cardiomyocytes from which the intracellular records were obtained. Aged $P g c-1 \beta^{-/}$hearts showed the highest arrhythmic incidences compared to the remaining groups $(p<0.05)$. The latter groups showed similar, reduced, arrhythmic frequencies. Aged $\mathrm{Pgc}-1 \beta^{-/}$hearts were also the only experimental group that showed ectopic activity, monomorphic VT and polymorphic VT (Fig. 2b-d). The incidence of arrhythmias in hearts from young $P g c-1 \beta^{-/}$hearts was not distinguishable from their WT counterparts.

Figure 3 exemplifies the different forms of alternans in AP characteristics observed in a typical aged $P g c-1 \beta^{-/}$heart with each panel displaying (from top to bottom) AP waveforms, AP latencies, the first derivative, $\mathrm{d} V / \mathrm{d} t$, of the AP waveform, $\mathrm{APD}_{90}$ and RMP. This makes it possible to directly visualize alternans in one or more electrophysiological parameters. The panels demonstrate the possible combinations of alternans involving activation or recovery parameters. Thus, the alternans in (a) involves the recovery variable of $\mathrm{APD}_{90}$ alone while (b) demonstrates alternans in the activation variables of AP latency and $(\mathrm{d} V / \mathrm{d} t)_{\max }$ alone. In contrast, (c) and (d) exemplify simultaneous alternans involving both activation and recovery variables. They include the extreme situations resulting in alternate APs with higher/lower latencies and therefore lower/higher $(\mathrm{d} V / \mathrm{d} t)_{\max }$ associated with higher/lower (c) or lower/higher $\mathrm{APD}_{90}(\mathrm{~d})$. The second case (d) would correspond to the most pro-arrhythmic situation. The bottom control trace shows the (relatively constant) resting potentials through the alternans phenomena.

\section{Increased frequencies of alternans in $P g c-1 \beta^{-/-}$hearts}

The presence of alternans in one or more AP characteristics with variations in BCL is an established marker for the instability presaging development of arrhythmia (see Introduction). We first compared the number of beats showing alternans in maximum AP upstroke rate $(\mathrm{d} V / \mathrm{d} t)_{\max }$ (Fig. 4a), AP latency (Fig. 4b), AP duration to $90 \%$ recovery $\left(\mathrm{APD}_{90}\right)$ (Fig. 4c) and resting membrane potential (RMP) (Fig. 4d) in young and aged, WT and $P g c-1 \beta^{-/}$hearts through the incremental pacing protocol described above. Overall incidences of 
a(i)

(V)

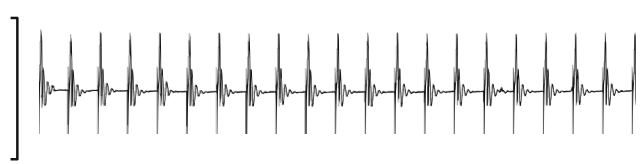

a(ii)

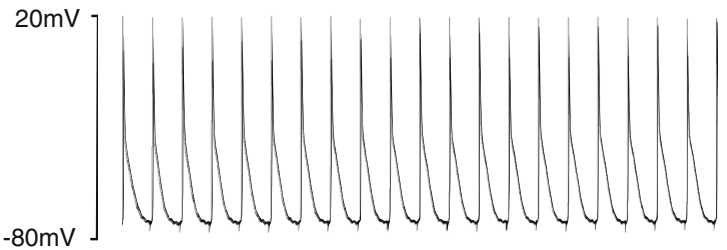

c(i)

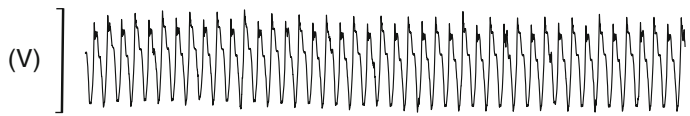

c(ii)

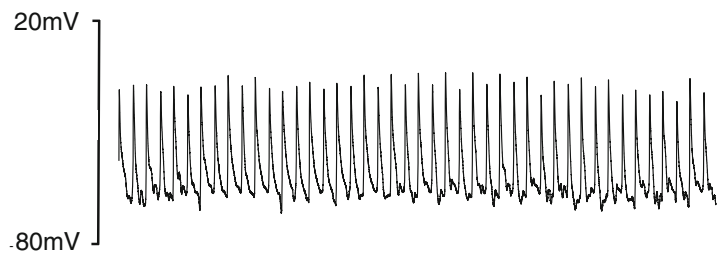

$\overline{0.2 \mathrm{~s}}$ b(i)

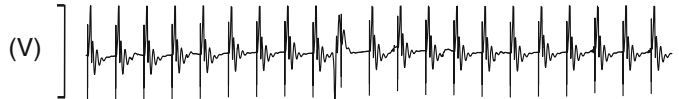

b(ii)

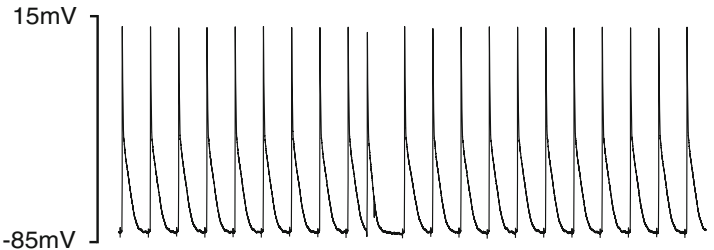

d(i)

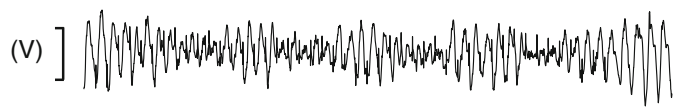

d(ii)

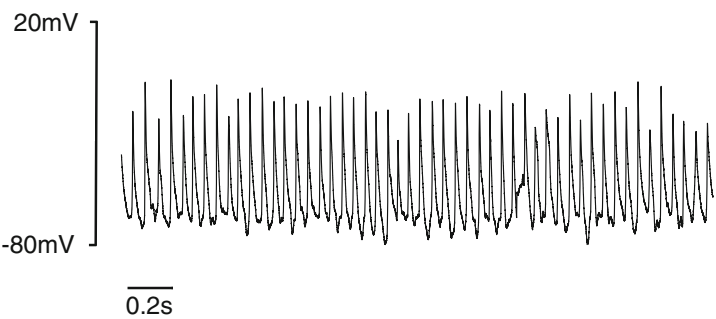

Fig. 2 a-d Parallel ECG (i) and intracellular AP recordings (ii) of regular activity at a $130 \mathrm{~ms}$ BCL in ventricles from heart from young WT mouse (a), and ectopic beat (b), monomorphic VT (c) and torsades de pointes (TdP) (d) VT in aged $P g c-1 \beta^{-/}$hearts

alternans were obtained for each heart by summing the number of beats of alternans at each BCL examined. The results were then compared between the experimental groups. $P g c$ $1 \beta^{-/}$hearts showed greater overall incidences of alternans compared to WT hearts in all the parameters $(\mathrm{d} V / \mathrm{d} t)_{\max }$, AP latency, $\mathrm{APD}_{90}$ and RMP. Thus, both young and aged $\mathrm{PgC}_{\mathrm{C}}$ $1 \beta^{-/}$hearts displayed an increased tendency to display alternans (Table 2).

Secondly, in addition to the above effects of genotype alone, genotype and age exerted interacting effects on the incidence of AP latency alternans $(p<0.05)$ and $\mathrm{APD}_{90}$ alternans $(p<0.05)$. Young WT hearts had the lowest incidences of AP latency alternans ( $575 \pm 51$ beats) with progressive increases in this incidence through the series: young $P g_{C}$ -

Table 1 Frequency of arrhythmia in the various experimental groups

\begin{tabular}{lllll}
\hline & Arrhythmic & $\begin{array}{l}\text { Non- } \\
\text { arrhythmic }\end{array}$ & Total $(n) \begin{array}{l}\text { Percentage } \\
\text { arrhythmic }\end{array}$ \\
\hline Young WT & 4 & 19 & 23 & 17.4 \\
Aged WT & 3 & 16 & 19 & 15.8 \\
$\begin{array}{l}\text { Young } \\
\quad P g c-1 \beta^{-/}\end{array}$ & 4 & 17 & 21 & 19.0 \\
$\begin{array}{l}\text { Aged } P g c-1 \beta^{--} \\
\text {Pged }\end{array}$ & $12^{*}$ & 13 & 25 & $48^{*}$ \\
\hline
\end{tabular}

${ }^{*} p<0.05$
$1 \beta^{-/}$hearts (785 \pm 78 beats), aged WT hearts $(790 \pm 33$ beats) and aged $P g c-1 \beta^{-/}$hearts $(923 \pm 81$ beats $)$, with the last group showing the greatest amount of AP latency alternans. Post hoc testing demonstrated significantly more AP latency alternans in young $P g c-1 \beta^{-/}$hearts compared to that in young WT hearts $(p<0.01)$ and that in aged $P g c-1 \beta^{-/}$ hearts compared to that in young WT hearts $(p<0.001)$. A similar pattern emerged in post hoc testing for $\mathrm{APD}_{90}$ alternans: all remaining groups showed significantly more alternans than young WT hearts (young WT vs young $\mathrm{Pgc}$ $1 \beta^{-/}, 726 \pm 65$ vs $1068 \pm 53$ beats, $p<0.001$; young WT vs aged WT, $726 \pm 65$ vs $1040 \pm 37$ beats, $p=0.001$; young WT vs aged $P g c-1 \beta^{-/}, 726 \pm 65$ vs $1107 \pm 60$ beats $\left.p<0.0001\right)$.

\section{Alternans at longer BCLs, with longer episodes, and involving multiple AP parameters in Pgc-1 $\boldsymbol{\beta}^{-/-}$hearts}

Figure 4 also displays the distribution of alternans in each parameter across different BCLs for each experimental group. It is apparent that there are greater incidences of alternans at longer BCLs in $P g c-1 \beta^{-/}$hearts than those in WT hearts. This suggests that they have a greater tendency to instability even at lower heart rates. In addition to the absolute burden of alternans described previously, we quantified the number of discrete sequences of alternans per protocol, the maximum 
Fig. 3 Examples of alternans phenomena comparing records of AP waveform, AP latency, (dV/ $\mathrm{d} t), \mathrm{APD}_{90}$ and $\mathrm{RMP}$ respectively in each panel. In a, alternans exclusively involves the recovery variable $\mathrm{APD}_{90}$ while in $\mathbf{b}$, it involves the activation variables of AP latency and $(\mathrm{d} V / \mathrm{d} t)$ alone. In $\mathbf{c}$ and $\mathbf{d}$, there is simultaneous alternans involving both activation and recovery variables. These include situations in which the alternating action potentials with higher/lower latencies and therefore lower/higher $(\mathrm{d} V / \mathrm{d} t)_{\max }$ show either higher/lower (c) or lower/higher (d) $\mathrm{APD}_{90}$, respectively a
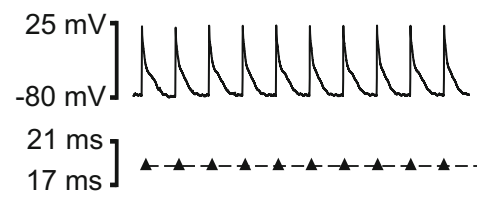

$150 \mathrm{Vs}^{-1}$

$-25 \mathrm{Vs}^{-1}$

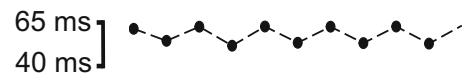

$\left.\begin{array}{c}-60 \mathrm{mV} \\ -100 \mathrm{mV}\end{array}\right]+-$

C

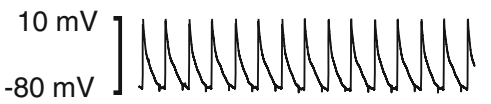

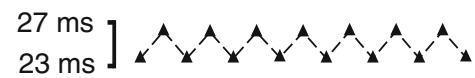

$\left.\begin{array}{l}150 \mathrm{Vs}^{-1} \\ -25 \mathrm{Vs}^{-1}\end{array}\right]$

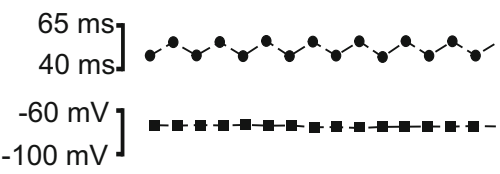

b
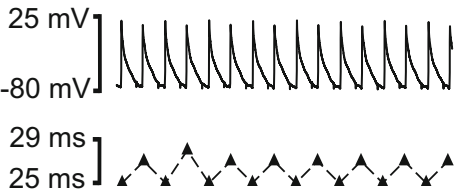

$150 \mathrm{Vs}^{-1}$

ليليليليليليليليليليليليليليليليلـ

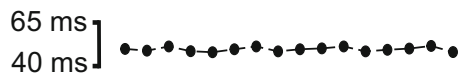

$-60 \mathrm{mV}$

$-100 \mathrm{mV}$

d

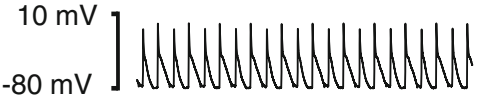

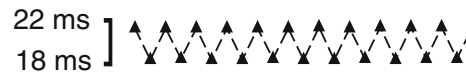

$150 \mathrm{Vs}^{-1}$
$-25 \mathrm{Vs}^{-1}$

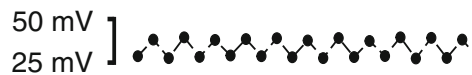

$-60 \mathrm{mV}$

$-100 \mathrm{mV}$ duration of alternans as well as the amount of simultaneous alternans between multiple parameters.

First, there were no distinguishable differences in the number of discrete episodes of alternans in $(\mathrm{d} V / \mathrm{d} t)_{\max }, \mathrm{APD}_{90}$ or RMP between young and aged, $P g c-1 \beta^{-/}$and WT hearts. In contrast, aged $P g c-1 \beta^{-/}$hearts showed a higher number of discrete runs of AP latency alternans than young WT hearts $(11.0 \pm 1.24$ vs $7.43 \pm 0.58$ runs of alternans; $p<0.05)$.

Secondly, the maximum duration of individual alternans episodes, whether involving $(\mathrm{d} V / \mathrm{d} t)_{\max }$, AP latency, $\mathrm{APD}_{90}$
Fig. 4 Incidence of alternans out of 100 beats at each BCL in the activation variables of maximum AP upstroke rate $(\mathrm{d} V / \mathrm{d} t)_{\max }(\mathbf{a})$, AP latency (b), and the recovery variables of AP duration to $90 \%$ recovery $\left(\mathrm{APD}_{90}\right)(\mathbf{c})$ and resting membrane potential (RMP) (d) in young and aged, WT and $P g c$ $1 \beta^{-/}$hearts through the incremental pacing protocol a

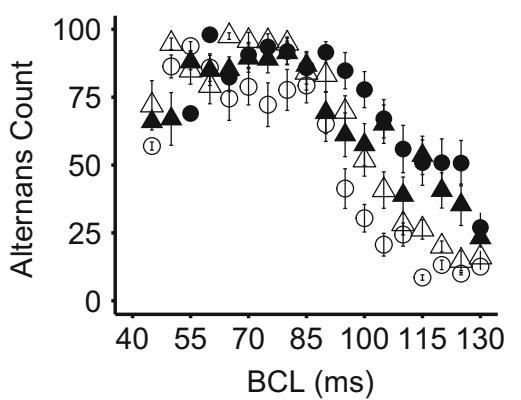

C

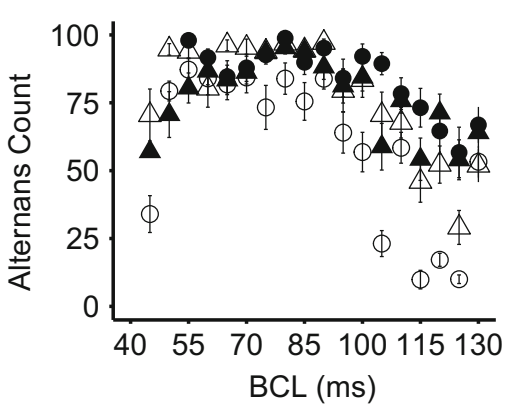

b

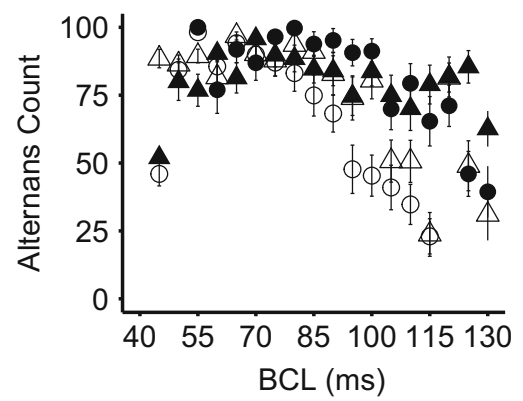

d

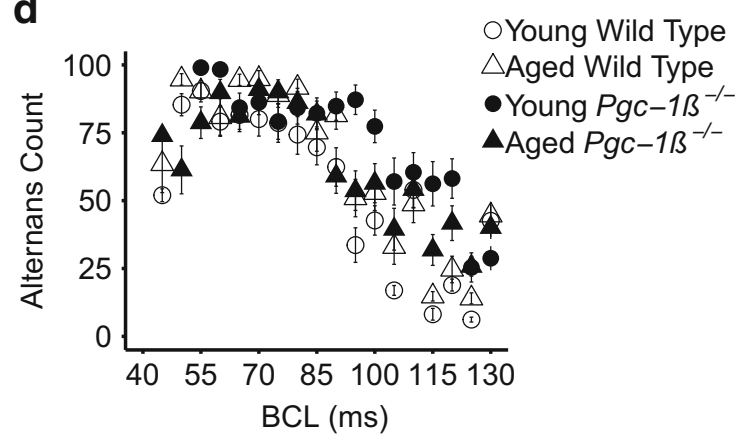


Table 2 Results of ANOVA comparisons of alternans features in $P g C-1 \beta^{-1}$ and WT hearts. Values represent number of beats out of 1600 beats

\begin{tabular}{lllll}
\hline & AP parameter & Pgc-1 $\beta^{-/}$ & WT & $p$ value \\
\hline Overall incidences of alternans (beats) & $(\mathrm{d} V / \mathrm{d} t)_{\max }$ & $872 \pm 42$ & $659 \pm 41$ & $p<0.0001$ \\
& AP latency & $928 \pm 49$ & $672 \pm 35 ;$ & $p<0.001$ \\
& APD $_{90}$ & $1089 \pm 40$ & $868 \pm 46$ & $p<0.001$ \\
& RMP & $852 \pm 42$ & $694 \pm 44$ & $p=0.01$ \\
Maximum duration of alternans episodes (beats) & $(\mathrm{d} V / \mathrm{d} t)_{\max }$ & $535 \pm 41$ & $404 \pm 36$ & $p<0.05$ \\
& AP latency & $611 \pm 46$ & $456 \pm 34$ & $p<0.01$ \\
& APD & $682 \pm 57$ & $509 \pm 44$ & $p<0.05$ \\
& RMP & $417 \pm 35$ & $312 \pm 32$ & $p<0.05$ \\
\hline
\end{tabular}

or RMP, was significantly longer in $P g c-1 \beta^{-/}$hearts than that in WT hearts. The maximum duration of alternans episodes involving AP latency also showed significant interactive effects of age and genotype $(p<0.05)$. Post hoc testing demonstrated that young $P g c-1 \beta^{-/}$hearts showed longer durations of AP latency alternans than young WT hearts $(683 \pm 62$ vs $406 \pm 50$ beats; $p<0.01$ ).

Thirdly, alternans simultaneously involving different AP characteristics were observed within the same heart. This could involve situations in which the alternating high/low AP latencies or reduced/increased $(\mathrm{d} V / \mathrm{d} t)_{\max }$ coincided with higher/lower $\mathrm{APD}_{90}$ values (Fig. 3c), or in the more proarrhythmic pattern, occurred out of phase with higher/lower $\mathrm{APD}_{90}$ values (Fig. 3d). Pgc-1 $\beta^{-/}$hearts showed more frequent simultaneous $(\mathrm{d} V / \mathrm{d} t)_{\max }$ and $\mathrm{APD}_{90}$ alternans compared to WT hearts $(72.15 \pm 2.22$ vs $64.97 \pm 3.03 \%$ of beats, respectively; $p=0.05$ ), with similar occurrences of both patterns of alternans. $P g c-1 \beta^{-/}$hearts also showed more frequent simultaneous $\mathrm{APD}_{90}$ and AP latency alternans $(74.03 \pm 2.92$ vs $65.11 \pm 2.61 \%$ of beats; $p<0.05)$. In this case, a greater number of beats assumed the more pro-arrhythmic pattern (697 \pm 58 vs $537 \pm 43$ beats; $p<0.05$ ). The incidence of the more pro-arrhythmic pattern of alternans was also significantly affected by interactions between age and genotype $(p<0.05)$. Post hoc Tukey tests demonstrated that young Pgc- $1 \beta^{-/}$hearts showed higher incidences of simultaneous alternans than young WT hearts $(p=0.01)$.

Finally, we quantified the amplitude of alternans where this occurred, by calculating the mean differences between successive peak and trough values in each parameter. These findings contrastingly demonstrated no significant variations between the groups.

\section{Altered action potential characteristics in young and aged Pgc-1 $\beta^{-/-}$hearts}

These differences in electrophysiological stability and proarrhythmic tendency were then correlated with differences in AP activation and recovery characteristics over the range of BCLs explored. Figure 5 plots the activation variables of $(\mathrm{d} V /$ $\mathrm{d} t)_{\max }$ (a) and AP latency (b) as well as the recovery variables of $\mathrm{APD}_{90}$, (c) RMP (d) and diastolic interval, DI, (given by the time between the action potential peak and the preceding

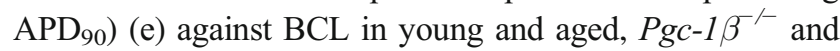
WT hearts. All data varied monotonically with BCL and so their overall magnitudes could be compared by the areas beneath their curves. Table 3 demonstrates that hearts with the $P g c-1 \beta^{-/}$genotype have lower $(\mathrm{d} V / \mathrm{d} t)_{\max }$ values and increased AP latencies relative to WT (both $p<0.001$ ). However, there were no detectable effects of either ageing or any interaction between genotype and ageing on $(\mathrm{d} V / \mathrm{d} t)_{\max }$. In contrast, neither $\mathrm{APD}_{90}$ nor RMPs were influenced by genotype alone. However, $\mathrm{APD}_{90}$ was longer in aged $P g c-1 \beta^{-/}$ hearts than that in young $P g c-1 \beta^{-/}$hearts $(p<0.05)$, and RMP greater in aged than young hearts.

\section{Wavelength as the basis for arrhythmic substrate}

The findings above demonstrate pro-arrhythmic features in aged $P g c-1 \beta^{-/}$hearts. Further quantification demonstrated increased alternans in both young and aged $P g c-1 \beta^{-/}$hearts. This in turn correlated with altered AP activation characteristics as reflected in $(\mathrm{d} V / \mathrm{d} t)_{\max }$ and AP latency, as opposed to the recovery characteristics, $\mathrm{APD}_{90}$ and RMP. The following analyses further tested the hypothesis that activation and not recovery parameters are the primary determinant of arrhythmia in this system.

First, hearts were stratified by arrhythmic and nonarrhythmic phenotypes, regardless of genotype or age. AP parameters observed prior to the onset of either arrhythmia or entry into 2:1 block were then compared. Arrhythmic hearts $(n=20)$ showed lower $(\mathrm{d} V / \mathrm{d} t)_{\max }$ and longer AP latencies than non-arrhythmic hearts $(n=68)\left((\mathrm{d} V / \mathrm{d} t)_{\max }\right.$, $67.29 \pm 6.85$ vs $87.66 \pm 3.28 \mathrm{~V} \mathrm{~s}^{-1}, p<0.05$; AP latencies $22.25 \pm 1.50$ vs $18.64 \pm 0.88 \mathrm{~ms}, p<0.05$, respectively). Diastolic interval $\left(\mathrm{DI}_{90}\right)$ durations were calculated from the $\mathrm{APD}_{90}$ time to the next action potential peak; thus, they were consequently altered as expected from the altered AP rise times $(27.43 \pm 1.53$ vs $31.54 \pm 1.09 \mathrm{~ms} ; p<0.05)$. There were no significant differences between their $\mathrm{APD}_{90}(32.75 \pm 1.22$ and $34.79 \pm 0.92 \mathrm{~ms})$ and RMPs $(-73.81 \pm 1.16 \mathrm{vs}$ 
Fig. 5 Dependence of maximum rate of AP depolarization, $(\mathrm{d} V /$ $\mathrm{d} t)_{\max }(\mathbf{a})$, AP latency (b), $\mathrm{APD}_{90}$ (c), RMP (d) and DI (e) on BCL in young and aged, WT and $P g c$ $1 \beta$ hearts
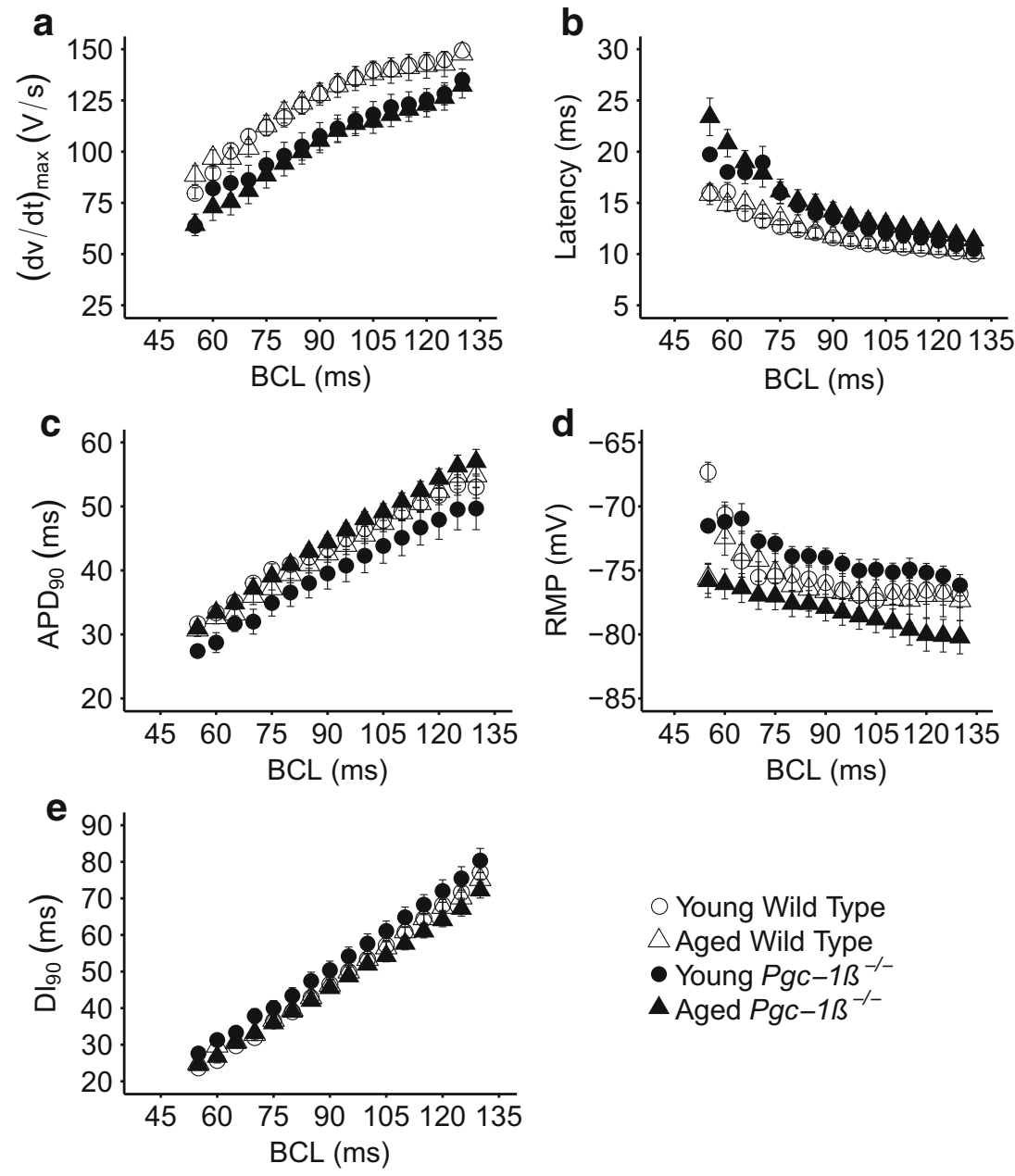

Young Wild Type

$\triangle$ Aged Wild Type

- Young Pgc-1 $1 \AA^{-/-}$

$\Delta$ Aged $P g C-1 \beta^{-/}$
$-73.60 \pm 0.72 \mathrm{mV}$ ). These findings implicate AP activation rather than recovery parameters in the initiation of arrhythmia.

Secondly, previous reports have correlated alternans characteristics to arrhythmic tendency in both monogenic murine models as well as in clinical situations. Arrhythmic syndromes primarily attributed to repolarisation abnormalities, exemplified by the murine $\operatorname{Scn} 5 a+/ \triangle K P Q$ model, were associated with alterations in the relationship between $\mathrm{APD}_{90}$ and VERP with varying DI $[33,35,41]$. In contrast, arrhythmia attributed to altered conduction in $\operatorname{Scn} 5 \mathrm{a}^{+/-}$hearts was associated with altered relationships between active AP wavelengths, $\lambda$, and BCL [39] or resting wavelength $\lambda_{0}$ [34]. Figure 6 illustrates the outcome of analyses testing both assumptions. These demonstrated indistinguishable limiting slopes in restitution plots of $\mathrm{APD}_{90}$ against $\mathrm{DI}_{90}$ in all the four experimental groups (Fig. 6a), in opposition to the prediction from the first hypothesis. We then proceeded to determine $\lambda$, calculated as the product of conduction velocity represented by 1 / (AP latency) and the corresponding VERP at each BCL. This was derived by interpolating values from the VERP obtained during the S1S2 protocol at a BCL of $125 \mathrm{~ms}$ and from the VERP obtained from the BCL during incremental pacing prior to loss of 1:1 stimulus capture. Young and aged WT hearts showed similar $\lambda$-BCL and $\lambda-\lambda_{0}$ plots (Fig. 6b, c). However, $P g c-1 \beta^{-/}$hearts showed lower plateau $\lambda$ values compared to WT hearts, particularly with ageing. This would be consistent with the relative arrhythmic tendencies in the four experimental groups reported here. Further strengthening this hypothesis, the mean wavelengths immediately prior to termination of the protocol into either arrhythmia or 2:1 block were significantly different $(p=0.01)$ at $4.4 \pm 0.31(n=20)$ for arrhythmic versus $5.4 \pm 0.20(n=68)$ for non-arrhythmic hearts.

\section{Discussion}

The present study explored pro-arrhythmic phenotypes and their age-dependence in murine hearts deficient in the key mitochondrial upregulator, $P g c-1 \beta$, previously associated with metabolic dysfunction. Previous molecular and cellular studies in murine $P g c-1 \beta^{-/}$cardiomyocytes had confirmed down-regulation of genes related to oxidative 


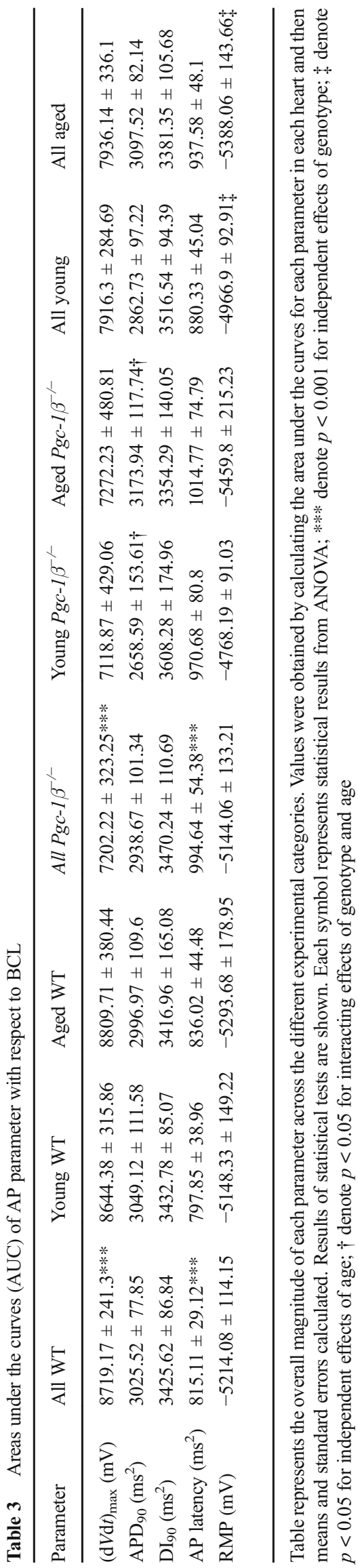

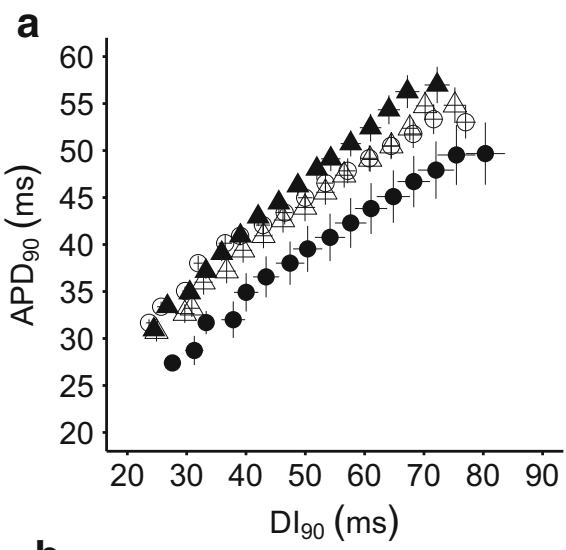

b

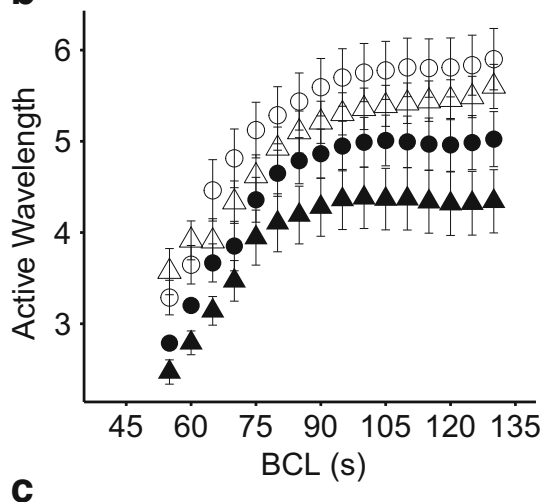

C

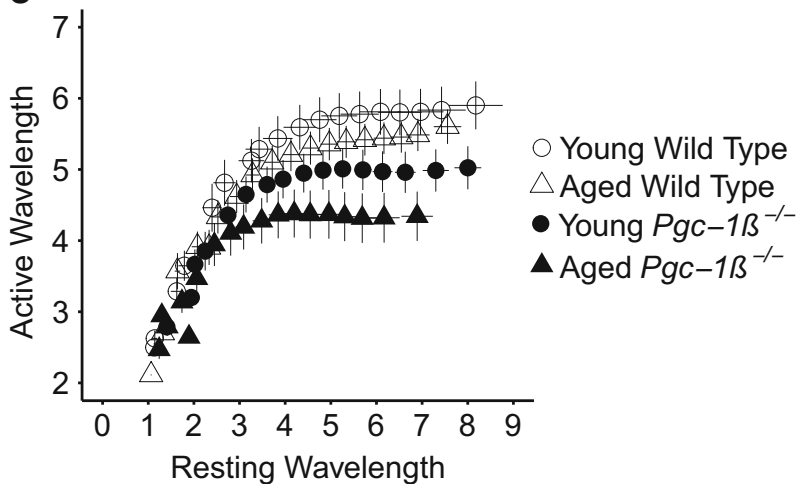

Fig. 6 Restitution plots of $\mathrm{APD}_{90}$ against $\mathrm{DI}_{90}$ (a) and of active $\mathrm{AP}$ wavelength (b) and passive wavelengths (c) observed at different BCLs through the incremental pacing procedure in young and aged WT and $P g c-1 \beta^{-/}$hearts

phosphorylation, electron transport and the Krebs cycle and upregulation of genes related to cardiac hypertrophy, hypoxia and heart failure [17]. Their fluometric studies demonstrated cellular diastolic $\mathrm{Ca}^{2+}$ transients, some forming $\mathrm{Ca}^{2+}$ waves producing temporal and spatial $\mathrm{Ca}^{2+}$ heterogeneities. Conventional patch clamp studies demonstrated positive voltage shifts in $\mathrm{Ca}^{2+}$ current inactivation, increased $\mathrm{Na}^{+}$, and transient and inwardly rectifying $\mathrm{K}^{+}$currents under conditions of intracellular $\mathrm{Ca}^{2+}$ buffering. These findings together accompanied potentially pro-arrhythmic oscillatory resting potentials, early and delayed afterdepolarisations, and burst action potential firing on sustained current injection potentially related to AP alternans, and ventricular tachycardia [17]. 
These findings corroborated specifically for the $\mathrm{Pgc}-1 \beta^{-/-}$ model broader associations between energetic dysfunction and increased reactive oxygen species production [16], the latter affecting voltage-dependent $\mathrm{Na}^{+}$and $\mathrm{K}^{+}$current $[32$, 48], sarcolemmal $\mathrm{K}_{\text {ATP }}$ channel function, $\mathrm{Na}^{+}$and $\mathrm{Ca}^{2+}$ channel inactivation, late $\mathrm{Na}^{+}$current and ryanodine receptor function [19]. Finally, the accompanying ATP/ADP depletion is known to open sarcolemmal ATP-sensitive $\mathrm{K}^{+}$channels $\left(\operatorname{sarcK}_{\text {ATP}}\right)[2]$.

Such changes potentially affect cell-cell coupling [43], AP conduction [32], repolarisation and refractoriness [48], and predispose to alternans and $\mathrm{Ca}^{2+}$-mediated pro-arrhythmic triggering [45]. The present experiments now explore and quantify the latter electrophysiological, potentially pro-arrhythmic, consequences in isolated perfused intact murine hearts hitherto employed to explore murine models modelling specific human monogenic channelopathies. [19]. Utilisation of intracellular cardiomyocyte recordings in this study made it possible to determine resting membrane potentials (RMPs), AP amplitudes, and provided sufficient bandwidth to follow maximum rates of AP depolarisation $(\mathrm{d} V / \mathrm{d} t)_{\max }$, measurements not possible with monophasic action potential recordings used previously. Additional simultaneous whole-heart ECG recordings allowed correlation of these cellular findings with arrhythmic events at the whole-organ level. Finally, use of additional experimental groups made it possible to assess and compare effects of ageing on the $P g c-1 \beta^{-/}$and WT phenotypes.

This study is the first to establish an age-dependent proarrhythmic phenotype in $\mathrm{Pgc}-1 \beta^{-/-}$murine hearts and the electrophysiological basis for this. The pro-arrhythmic phenotype shown by aged $P g c-1 \beta^{-/}$hearts parallels epidemiological clinical data reporting age-dependent arrhythmic risks in metabolic disease. Early or delayed afterdepolarisation phenomena, previously implicated in arrhythmic triggering processes $[6,46]$, were not observed, making a dependence of the arrhythmic phenotype on such triggering events less likely.

$P g c-1 \beta^{-/-}$hearts irrespective of age showed an increased incidence of alternans in AP activation $\left((\mathrm{d} V / \mathrm{d} t)_{\max }\right.$ and AP latency) and recovery ( $\mathrm{APD}_{90}$ and $\left.\mathrm{RMP}\right)$ parameters. These occurred at lower pacing frequencies than in WT hearts, consistent with greater instability in hearts with metabolic compromise. Arrhythmic substrate resulting from repolarisation abnormalities gives restitution plots of $\mathrm{APD}_{90}$ against $\mathrm{DI}_{90}$ with distinct gradient properties from those of WT hearts. However, the restitution loci in $\mathrm{Pgc}-1 \beta^{-/}$hearts showed limiting slopes indistinguishable from WT hearts. Instead, $P g c-$ $1 \beta^{-/}$hearts showed compromised AP activation as reflected in $(\mathrm{d} V / \mathrm{d} t)_{\max }$ and AP latency, and shorter effective refractory periods than WT hearts. Furthermore, the onset of arrhythmia was associated with compromised AP activation but normal AP recovery.
These findings localise the arrhythmic substrate to defects in AP activation. $P g c-1 \beta^{-/}$hearts had altered AP wavelength $(\lambda)$ properties, determined from the conduction velocity - effective refractory period product. Young and aged WT hearts showed similar $\lambda$-BCL and $\lambda-\lambda_{0}$ plots whereas young and aged $P g c-1 \beta^{-/}$hearts showed reduced values of $\lambda$ through all BCLs - an effect more marked in the aged $P g c-1 \beta^{-/}$ hearts. This finding is an exact parallel of previous demonstrations of the presence of arrhythmic phenotypes and of proarrhythmic alternans phenomena.

The present observations in $P g c-1 \beta^{-/}$hearts parallel features reported in $S c n 5 a^{+-}$and $R y R 2-\mathrm{P} 2328 \mathrm{~S} / \mathrm{P} 2328 \mathrm{~S}$ cardiac models for Brugada syndrome and catecholaminergic polymorphic ventricular tachycardia, respectively [33-35, 39]. Recent work had similarly attributed arrhythmic substrate in RyR2-P2328S/P2328S hearts to slowed AP conduction accompanying reductions in $(\mathrm{d} V / \mathrm{d} t)_{\max }[53]$ and in $\mathrm{Na}^{+}$currents to extents comparable to those observed in $\mathrm{Na}_{\mathrm{V}} 1.5$ haploinsufficient $S c n 5 a^{+/-}$hearts [26, 27]. These reductions in $\mathrm{Na}^{+}$currents in the $R y R 2-\mathrm{P} 2328 \mathrm{~S} / \mathrm{P} 2328 \mathrm{~S}$ cardiomyocytes were attributed to effects of altered $\mathrm{Ca}^{2+}$ homeostasis upon $\mathrm{Na}_{\mathrm{v}} 1.5$ expression [39] and/or acutely upon $\mathrm{Na}_{\mathrm{v}} 1.5$ function $[26,27]$. RyR $2-\mathrm{P} 2328 \mathrm{~S} / \mathrm{P} 2328 \mathrm{~S}$ and $P g c-1 \beta^{-/-}$ cardiomyocytes share abnormal $\mathrm{Ca}^{2+}$ handling phenotypes [17]. The normal or even enhanced $\mathrm{Na}^{+}$currents in patchclamped $P g c-1 \beta^{-/}$cardiomyocytes [17] are compatible with acute effects of their altered $\mathrm{Ca}^{2+}$ homeostasis upon membrane excitability in cardiomyocytes in intact tissue [26, 31, $39,42]$. Thus, patch-clamped WT myocytes also show respective acutely reduced, or increased, $\mathrm{Na}^{+}$current and $(\mathrm{d} V / \mathrm{d} t)_{\max }$, with increases in, or sequestration of, the pipette $\left[\mathrm{Ca}^{2+}\right]$ [7]. These effects could reflect $\mathrm{Ca}^{2+}{ }_{-} \mathrm{Na}_{\mathrm{v}} 1.5$ interactions involving direct $\mathrm{Ca}^{2+} \mathrm{Na}_{\mathrm{v}} 1.5$ binding at an EF hand motif close to the $\mathrm{Na}_{\mathrm{v}} 1.5$ carboxy-terminal [50] or indirect $\mathrm{Ca}^{2+}$ binding involving an additional 'IQ' domain binding site for $\mathrm{Ca}^{2+} / \mathrm{CaM}$ in the $\mathrm{Na}_{\mathrm{v}} 1.5 \mathrm{C}$-terminal region $[15,37,47]$. The present findings thus throw light on possible, more widespread, effects of altered intracellular $\mathrm{Ca}^{2+}$ homeostasis on AP propagation in addition to identifying electrophysiological mechanisms underlying the arrhythmic risk associated with metabolic disturbance.

Acknowledgements We acknowledge the financial support from the Medical Research Council (MR/M001288/1); the Wellcome Trust (105727/Z/14/Z); the British Heart Foundation (PG/14/79/31102 and PG/15/12/31280), Sudden arrhythmic death syndrome (SADS) UK; The McVeigh Benefaction and by the Fundamental Research Grant Scheme (FRGS/2/2014/SKK01/PERDANA/02/1), Ministry of Education, Malaysia.

\section{Compliance with ethical standards}

Conflict of interest The authors declare that they have no conflict of interest. 
Open Access This article is distributed under the terms of the Creative Commons Attribution 4.0 International License (http:// creativecommons.org/licenses/by/4.0/), which permits unrestricted use, distribution, and reproduction in any medium, provided you give appropriate credit to the original author(s) and the source, provide a link to the Creative Commons license, and indicate if changes were made.

\section{References}

1. Adabag S, Huxley RR, Lopez FL, Chen LY, Sotoodehnia N, Siscovick D, Deo R, Konety S, Alonso A, Folsom AR (2015) Obesity related risk of sudden cardiac death in the atherosclerosis risk in communities study. Heart 101:215-221. doi:10.1136/ heartjnl-2014-306238

2. Akar FG, O'Rourke B (2011) Mitochondria are sources of metabolic sink and arrhythmias. Pharmacol \& Ther 131:287-294. doi: 10.1016/j.pharmthera.2011.04.005

3. Arany Z, He H, Lin J, Hoyer K, Handschin C, Toka O, Ahmad F, Matsui T, Chin S, Wu P-H, Rybkin II, Shelton JM, Manieri M, Cinti S, Schoen FJ, Bassel-Duby R, Rosenzweig A, Ingwall JS, Spiegelman BM (2005) Transcriptional coactivator PGC-1 alpha controls the energy state and contractile function of cardiac muscle. Cell Metab 1:259-271. doi:10.1016/j.cmet.2005.03.002

4. Arany Z, Novikov M, Chin S, Ma Y, Rosenzweig A, Spiegelman BM (2006) Transverse aortic constriction leads to accelerated heart failure in mice lacking PPAR-gamma coactivator 1alpha. Proc Natl Acad Sci U S A 103:10086-10091. doi:10.1073/pnas.0603615103

5. Balasubramaniam R, Chawla S, Grace AA, Huang CL-H (2005) Caffeine-induced arrhythmias in murine hearts parallel changes in cellular $\mathrm{Ca}(2+)$ homeostasis. Am J Physiol Heart Circ Physiol 289: H1584-H1593. doi:10.1152/ajpheart.01250.2004

6. Balasubramaniam R, Chawla S, Mackenzie L, Schwiening CJ, Grace AA, Huang CL-H (2004) Nifedipine and diltiazem suppress ventricular arrhythmogenesis and calcium release in mouse hearts. Pflugers Arch 449:150-158. doi:10.1007/s00424-004-1321-2

7. Casini S, Verkerk AO, van Borren MMGJ, van Ginneken ACG, Veldkamp MW, de Bakker JMT, Tan HL (2009) Intracellular calcium modulation of voltage-gated sodium channels in ventricular myocytes. Cardiovasc Res 81:72-81. doi:10.1093/cvr/cvn274

8. Deo R, Albert CM (2012) Epidemiology and genetics of sudden cardiac death. Circulation 125:620-637

9. Dillon LM, Rebelo AP, Moraes CT (2012) The role of PGC-1 coactivators in aging skeletal muscle and heart. IUBMB Life 64: 231-241. doi:10.1002/iub.608

10. Dou Y, Arlock P, Arner A (2007) Blebbistatin specifically inhibits actin-myosin interaction in mouse cardiac muscle. Am J Physiol Cell Physiol 293:C1148-C1153. doi:10.1152/ajpcell.00551.2006

11. Farman GP, Tachampa K, Mateja R, Cazorla O, Lacampagne A, de Tombe PP (2008) Blebbistatin: use as inhibitor of muscle contraction. Pflugers Arch Eur J Physiol 455:995-1005. doi:10.1007/ s00424-007-0375-3

12. Fedorov VV, Lozinsky IT, Sosunov EA, Anyukhovsky EP, Rosen MR, Balke CW, Efimov IR (2007) Application of blebbistatin as an excitation-contraction uncoupler for electrophysiologic study of rat and rabbit hearts. Hear Rhythm 4:619-626. doi:10.1016/j.hrthm. 2006.12.047

13. Finck BN, Kelly DP (2006) PGC-1 coactivators: inducible regulators of energy metabolism in health and disease. J Clin Invest 116: 615-622. doi:10.1172/JCI27794

14. Goddard CA, Ghais NS, Zhang Y, Williams AJ, Colledge WH, Grace AA, Huang CL-H (2008) Physiological consequences of the P2328S mutation in the ryanodine receptor (RyR2) gene in genetically modified murine hearts. Acta Physiol 194:123-140. doi:10.1111/j.1748-1716.2008.01865.x

15. Grandi E, Herren AW (2014) CaMKII-dependent regulation of cardiac $\mathrm{Na}(+)$ homeostasis. Front Pharmacol 5:41. doi:10.3389/fphar. 2014.00041

16. Grivennikova VG, Kareyeva AV, Vinogradov AD (2010) What are the sources of hydrogen peroxide production by heart mitochondria? Biochim Biophys Acta 1797:939-944

17. Gurung IS, Medina-Gomez G, Kis A, Baker M, Velagapudi V, Neogi SG, Campbell M, Rodriguez-Cuenca S, Lelliott C, McFarlane I, Oresic M, Grace AA, Vidal-Puig A, Huang CL-H (2011) Deletion of the metabolic transcriptional coactivator PGC1 $\beta$ induces cardiac arrhythmia. Cardiovasc Res 92:29-38

18. Hatch F, Lancaster MK, Jones SA (2011) Aging is a primary risk factor for cardiac arrhythmias: disruption of intracellular $\mathrm{Ca}^{2+}$ regulation as a key suspect. Expert Rev Cardiovasc Ther 9:1059-1067. doi:10.1586/erc.11.112

19. Huang C (2017) Murine electrophysiological models of cardiac arrhythmogenesis. Physiol Rev 97:283-409

20. Huss JM, Imahashi K, Dufour CR, Weinheimer CJ, Courtois M, Kovacs A, Giguère V, Murphy E, Kelly DP (2007) The nuclear receptor ERR $\alpha$ is required for the bioenergetic and functional adaptation to cardiac pressure overload. Cell Metab 6:25-37. doi:10. 1016/j.cmet.2007.06.005

21. Ingwall JS, Weiss RG (2004) Is the failing heart energy starved?: on using chemical energy to support cardiac function. Circ Res 95: 135-145. doi:10.1161/01.RES.0000137170.41939.d9

22. Jeevaratnam K, Guzadhur L, Goh Y, Grace A, Huang CL-H (2016) Sodium channel haploinsufficiency and structural change in ventricular arrhythmogenesis. Acta Physiol 216:186-202. doi:10.1111/ apha. 12577

23. Jou CJ, Spitzer KW, Tristani-Firouzi M (2010) Blebbistatin effectively uncouples the excitation-contraction process in zebrafish embryonic heart. Cell Physiol Biochem 25:419-424. doi:10.1159/ 000303046

24. Kabunga P, Lau AK, Phan K, Puranik R, Liang C, Davis RL, Sue CM, Sy RW (2015) Systematic review of cardiac electrical disease in Kearns-Sayre syndrome and mitochondrial cytopathy. Int $\mathrm{J}$ Cardiol 181:303-310. doi:10.1016/j.ijcard.2014.12.038

25. Killeen MJ, Thomas G, Sabir IN, Grace AA, Huang CL-H (2008) Mouse models of human arrhythmia syndromes. Acta Physiol (Oxf) 192:455-469. doi:10.1111/j.1748-1716.2007.01822.x

26. King J, Wickramarachchi C, Kua K, Du Y, Jeevaratnam K, Matthews HR, Grace AA, Huang CL-H, Fraser JA (2013) Loss of Nav1.5 expression and function in murine atria containing the RyR2-P2328S gain-of-function mutation. Cardiovasc Res 99:751759. doi:10.1093/cvr/cvt141

27. King J, Zhang Y, Lei M, Grace A, Huang C-H, Fraser J (2013) Atrial arrhythmia, triggering events and conduction abnormalities in isolated murine RyR2-P2328S hearts. Acta Physiol 207:308323. doi:10.1111/apha.12006

28. Kucharska-Newton AM, Couper DJ, Pankow JS, Prineas RJ, Rea TD, Sotoodehnia N, Chakravarti A, Folsom AR, Siscovick DS, Rosamond WD (2010) Diabetes and the risk of sudden cardiac death, the Atherosclerosis Risk in Communities study. Acta Diabetol 47(Suppl 1):161-168. doi:10.1007/s00592-009-0157-9

29. Lelliott CJ, Medina-Gomez G, Petrovic N, Kis A, Feldmann HM, Bjursell M, Parker N, Curtis K, Campbell M, Hu P, Zhang D, Litwin SE, Zaha VG, Fountain KT, Boudina S, Jimenez-Linan M, Blount M, Lopez M, Meirhaeghe A, Bohlooly-Y M, Storlien L, Strömstedt M, Snaith M, Orešič M, Abel ED, Cannon B, VidalPuig A (2006) Ablation of PGC-1 $\beta$ results in defective mitochondrial activity, thermogenesis, hepatic function, and cardiac performance. PLoS Biol 4:2042-2056. doi:10.1371/journal.pbio. 0040369 
30. Leone TC, Kelly DP (2011) Transcriptional control of cardiac fuel metabolism and mitochondrial function. Cold Spring Harb Symp Quant Biol 76:175-182. doi:10.1101/sqb.2011.76.011965

31. Li M, Hothi S, Salvage S, Jeevaratnam K, Grace A, Huang C (2017) Arrhythmic effects of Epac-mediated ryanodine receptor activation in Langendorff-perfused murine hearts are associated with reduced conduction velocity. Clin Exp Pharmacol Physiol 44:686-692

32. Liu M, Liu H, Dudley SC (2010) Reactive oxygen species originating from mitochondria regulate the cardiac sodium channel. Circ Res 107:967-974. doi:10.1161/CIRCRESAHA.110.220673

33. Matthews GDK, Guzadhur L, Grace A, Huang CL-H (2012) Nonlinearity between action potential alternans and restitution, which both predict ventricular arrhythmic properties in Scn5a+/and wild-type murine hearts. J Appl Physiol 112:1847-1863. doi: 10.1152/japplphysiol.00039.2012

34. Matthews GDK, Guzadhur L, Sabir IN, Grace AA, Huang CL-H (2013) Action potential wavelength restitution predicts alternans and arrhythmia in murine Scn5a+/- hearts. J Physiol 591:41674188. doi:10.1113/jphysiol.2013.254938

35. Matthews GDK, Martin CA, Grace AA, Zhang Y, Huang CL-H (2010) Regional variations in action potential alternans in isolated murine Scn5a (+/-) hearts during dynamic pacing. Acta Physiol (Oxf) 200:129-146. doi:10.1111/j.1748-1716.2010.02138.x

36. Mootha VK, Lindgren CM, Eriksson K-F, Subramanian A, Sihag S, Lehar J, Puigserver P, Carlsson E, Ridderstråle M, Laurila E, Houstis N, Daly MJ, Patterson N, Mesirov JP, Golub TR, Tamayo P, Spiegelman B, Lander ES, Hirschhorn JN, Altshuler D, Groop LC (2003) PGC-1 $\alpha$-responsive genes involved in oxidative phosphorylation are coordinately downregulated in human diabetes. Nat Genet 34:267-273. doi:10.1038/ng1180

37. Mori M, Konno T, Ozawa T, Murata M, Imoto K, Nagayama K (2000) Novel interaction of the voltage-dependent sodium channel (VDSC) with calmodulin: does VDSC acquire calmodulin-mediated $\mathrm{Ca}(2+)-$ sensitivity? Biochemistry 39:1316-1323. doi:10.1021/bi9912600

38. Neubauer S (2007) The failing heart - an engine out of fuel. N Engl J Med 356:1140-1151. doi:10.1056/NEJMra063052

39. Ning F, Luo L, Ahmad S, Valli H, Jeevaratnam K, Wang T, Guzadhur L, Yang D, Fraser JA, Huang CL-H, Ma A, Salvage SC (2016) The RyR2-P2328S mutation downregulates Nav1.5 producing arrhythmic substrate in murine ventricles. Pflügers Arch Eur J Physiol 468:655-665. doi:10.1007/s00424-015-1750-0

40. R Core Team (2015) R: a language and environment for statistical computing. R Foundation for Statistical Computing, Vienna. ISBN: 3-900051-07-0. Available online at http://www.R-project.org/

41. Sabir IN, Li LM, Grace AA, Huang CL-H (2008) Restitution analysis of alternans and its relationship to arrhythmogenicity in hypokalaemic Langendorff-perfused murine hearts. Pflugers Arch Eur J Physiol 455:653-666. doi:10.1007/s00424-007-0327-y

42. Salvage SC, King JH, Chandrasekharan KH, Jafferji DIG, Guzadhur L, Matthews HR, Huang CL-H, Fraser JA (2015) Flecainide exerts paradoxical effects on sodium currents and atrial arrhythmia in murine RyR2-P2328S hearts. Acta Physiol 214:361375. doi:10.1111/apha.12505

43. Smyth JW, Hong TT, Gao D, Vogan JM, Jensen BC, Fong TS, Simpson PC, Stainier DYR, Chi NC, Shaw RM (2010) Limited forward trafficking of connexin 43 reduces cell-cell coupling in stressed human and mouse myocardium. J Clin Invest 120:266279. doi:10.1172/JCI39740

44. Sonoda J, Mehl IR, Chong L-W, Nofsinger RR, Evans RM (2007) PGC-1beta controls mitochondrial metabolism to modulate circadian activity, adaptive thermogenesis, and hepatic steatosis. Proc Natl Acad Sci U S A 104:5223-5228. doi:10.1073/pnas.0611623104

45. Terentyev D, Gyorke I, Belevych AE, Terentyeva R, Sridhar A, Nishijima Y, de Blanco EC, Khanna S, Sen CK, Cardounel AJ, Carnes CA, Györke S (2008) Redox modification of ryanodine receptors contributes to sarcoplasmic reticulum $\mathrm{Ca}(2+)$ leak in chronic heart failure. Circ Res 103:1466-1472

46. Thomas G, Killeen MJ, Gurung IS, Hakim P, Balasubramaniam R, Goddard CA, Grace AA, Huang CL-H (2007) Mechanisms of ventricular arrhythmogenesis in mice following targeted disruption of KCNE1 modelling long QT syndrome 5. J Physiol 578:99-114. doi:10.1113/jphysiol.2006.118133

47. Wagner S, Ruff HM, Weber SL, Bellmann S, Sowa T, Schulte T, Anderson ME, Grandi E, Bers DM, Backs J, Belardinelli L, Maier LS (2011) Reactive oxygen species-activated Ca/calmodulin kinase II $\delta$ is required for late $\mathrm{I}(\mathrm{Na})$ augmentation leading to cellular $\mathrm{Na}$ and Ca overload. Circ Res 108:555-565. doi:10.1161/CIRCRESAHA. 110.221911

48. Wang J, Wang H, Zhang Y, Gao H, Nattel S, Wang Z (2004) Impairment of HERG $\mathrm{K}(+)$ channel function by tumor necrosis factor-alpha: role of reactive oxygen species as a mediator. $\mathrm{J}$ BiolChem 279:13289-13292

49. Wickham H (2009) ggplot2: elegant graphics for data analysis. Springer-Verlag, New York

50. Wingo TL, Shah VN, Anderson ME, Lybrand TP, Chazin WJ, Balser JR (2004) An EF-hand in the sodium channel couples intracellular calcium to cardiac excitability. Nat Struct Mol Biol 11:219 225. doi: $10.1038 / \mathrm{nsmb} 737$

51. Yeung C-Y, Lam KS-L, Li S-W, Lam K-F, Tse H-F, Siu C-W (2012) Sudden cardiac death after myocardial infarction in type 2 diabetic patients with no residual myocardial ischemia. Diabetes Care 35: 2564-2569. doi: $10.2337 / \mathrm{dc} 12-0118$

52. Zhang Y, Fraser JA, Jeevaratnam K, Hao X, Hothi SS, Grace AA, Lei M, Huang CL-H (2011) Acute atrial arrhythmogenicity and altered $\mathrm{Ca}(2+)$ homeostasis in murine RyR2-P2328S hearts. Cardiovasc Res 89:794-804. doi:10.1093/cvr/cvq229

53. Zhang Y, Wu J, Jeevaratnam K, King JH, Guzadhur L, Ren X, Grace AA, Lei M, Huang CL-H, Fraser JA (2013) Conduction slowing contributes to spontaneous ventricular arrhythmias in intrinsically active murine RyR2-P2328S hearts. J Cardiovasc Electrophysiol 24:210-218. doi:10.1111/jce.12015

54. Zoni-Berisso M, Lercari F, Carazza T, Domenicucci S (2014) Epidemiology of atrial fibrillation: European perspective. Clin Epidemiol 6:213-220. doi:10.2147/CLEP.S47385 